\title{
ENTREVISTA CON FELIPE GONZÁLEZ VICÉN
}

1

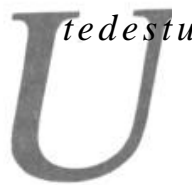

uvo nladécadadelos 30 enAlemania. Allítuvoocasión de vivir tanto la gran Universidad alemana como la ascensión del nazismo. ¿Qué impresiones producía a un joven estudioso español la Alemania de aquellos años? ¿Qué recuerdos conserva usted? ¿Podría hablarnos de sus años de formación en Europa y de su peripecia académica desde la obtención, en 1935, de la cátedra de Filosofía del Derecho de la Universidad de Sevilla?

Mi biografía académica no difiere en mucho de la de mis compañeros de generación. Estudié en las Universidades de Valladolid, Salamanca y Madrid. Pensionado por la Junta de Ampliación de Estudios en Italia, Alemania e Inglaterra. En 1932, Profesor Auxiliar -como se decía entonces- en la Facultad de Derecho de la Universidad de Valladolid. En 1935, catedrático por oposición de Filosofía del Derecho de Sevilla. En 1936, destituido de mi cátedra e inhabilitado para todo cargo docente. En 1937, y gracias a amigos fraternales, pude escapar de España. Luego, la vida del emigrado: Francia, Inglaterra, Holanda, la lucha interminable por el permiso de residencia y el de trabajo. Finalmente en Alemania, en casa de la familia de mi mujer donde me sorprendió el estallido de la guerra, y donde pude aguantar con traducciones y dando clases de español hasta el fin de la contienda. En 1946 repuesto en la cátedra y destinado forzosamente a La Laguna. Desde entonces, aquí estoy, aunque he podido prácticamente haber pedido el traslado a todas las Universidades españolas. Medito a veces en las palabras de Nietzsche: «El carácter de una persona se mide por su capacidad para la soledad».

Tanto en su tarea de traductor como en la de historiador de la filosofía jurídica usted ha trabajado fundamentalmente sobre el pensamiento alemán. Sin embargo, en las jóvenes generaciones de filósofos del Derecho de nuestro país ya no parece predominar el interés por la filosofía jurídica alemana, sino más bien por la angloamericana. ¿Cree usted que hay razones fundadas para este desplazamiento de interés, o que éste obedece en alguna medida a factores, digamos, imperiales? ¿Qué opinión le merece a usted la actual filosofía del Derecho alemana?

Sí, efectivamente, mi atención se ha dirigido casi siempre y de modo preferente al pensamiento alemán. También he traducido obras de otros idiomas e incluso he publicado trabajos sobre Hobbes, Berkeley, J. Austin, Vico y Guicciardini, pero, en lo esencial, es verdad lo que se afirma en la pregunta, y casi toda mi obra escrita está orientada o basada en fuentes alemanas. ¿A qué se debe esto? Para responder a este tipo de interrogantes es pre- 
ciso, mal que a uno le pese, bucear en las circunstancias biográficas de la persona. No podía ser de otra manera en mi caso. Yo estudié en Italia antes de ir a Alemania, y después pasé cerca de un año en Cambridge. Yo no sé si fue mi propio estado de ánimo -entonces tenía veinticuatro años de edadpero lo cierto es que sólo en Alemania encontré respuesta a las inquietudes y problemas que me aquejaban. Tan es así, que -esta vez sin pensión y a mi propia costa- tres o cuatro meses antes de la oposición volví a Berlín para encerrarme en la Staatsbibliothek y terminar allí mi «memoria» y mi trabajo de investigación. Yo no sé si mi preferencia por el pensamiento alemán no proviene también, en parte, de los consejos de mis colegas italianos, todos los cuales habían estado en Alemania, y me animaban incansablemente a ir allí, como si allí se encontrara la cúspide del saber. Aún cuando luego tuve ocasión de ver con mis propios ojos que esto naturalmente no era ni mucho menos verdad, sí me impresionó la seriedad en el trabajo que hallé entre los universitarios alemanes, el sincero e inquebrantable afán con que se esforzaban en llegar al último resquicio de los problemas, por ásperos y hoscos que éstos fueran. Pero lo que más me sorprendió y quedó grabado en la mente, fue el ver cómo profesores renombrados, juristas y filósofos, se dedicaban de modo pleno y exclusivo a la filosofía del Derecho. Ver, en suma, que ésta última no era, como yo tantas veces había visto, y habría de ver con harta frecuencia más adelante, algo así como un solaz o un divertimiento erudito escrito al margen de la labor seria de penalista, civilista o procesalista, sino un campo del saber por sí, de estructura y límites determinados, que había que indagar con un método propio. Los «filósofos del Derecho» trabajaban su disciplina con la vista fija en los que les habían precedido y siempre orientados hacia el horizonte filosófico del tiempo en que laboraban. Esta orientación que es, más bien, un entrelazamiento con las ideas por las que una época se entiende a sí misma, va a insertar también la filosofía del Derecho en la dialéctica de los sistemas filosóficos que se suceden a lo largo de la historia y es por eso, que, si seguimos el desarrollo de la filosofía del Derecho desde comienzos del idealismo alemán, que es cuando su denominación cobra carta de naturaleza, hasta los últimos sistemas neokantianos o fenomenológicos, veremos que tenemos ante nosotros un verdadero período filosófico en el más estricto sentido de la palabra. Un período en el que abundan las desviaciones y los cambios de perspectiva, pero todo penetrado por la voluntad unitaria de hallar respuesta a un número muy reducido de problemas.

Ésta es, aunque muy resumida y salpicada de alusiones biográficas, la respuesta que puedo dar a mi preferencia por el pensamiento alemán. Desde mis primeros años de formación postuniversitaria he creído, como hoy sigo creyendo, que la filosofía del Derecho como tal es, ante todo y sobre todo, una disciplina filosófica. No se trata de una opinión personal mía, sino de la de toda una época, y a ella se debe, sin duda, el incomparable florecimiento de la filosofía del Derecho española en aquellos lejanos años de 1931-1935. Una prueba de esta convicción general puede verse, si se me permite un recuerdo personal, en la composición del tribunal que juzgó mis oposiciones a cátedra, en el que figuraban dos de los más notables filósofos de entonces: M. García Morente y J. Caos. Se comprende que con esta idea de nuestra disciplina y esta formación, mi atención se dirigiera preferente- 
mente a una filosofía que, como la alemana, parecía hacer realidad aquella idea, y cuya filosofía del Derecho se insertaba por principio en el movimiento general de la reflexión filosófica.

Sobre el cambio de la influencia alemana por la anglosajona en nuestros jóvenes filósofos del Derecho, apenas si puedo decir algo. ¿Por qué fue decisiva la influencia francesa en España durante siglos, y no sólo en la literatura, sino en los mismos modos de vida? ¿Por qué, desde mediados del último siglo, esta influencia es sustituida lentamente por la influencia inglesa o alemana? Se trata de procesos muy complejos en los que juegan papel tanto sucesos nimios como importantes, la publicación de obras famosas, la labor de un maestro inolvidable. Quizás el desplazamiento de la filosofía alemana por la anglosajona se deba a la estructura consustancial a ambas. Un libro de filosofía inglesa, como, por ejemplo, un ensayo de Hume, puede leerse sin dificultad; podremos estar conformes o no con el autor, pero siempre pisamos terreno firme y podemos seguir sin dificultades el hilo del pensamiento. Una obra de filosofía alemana, por estar inscrita casi siempre en un círculo especulativo superior, se halla cargada de supuestos y razonamientos preliminares, deja entrever y da por sabidas muchas cosas que no explica y sólo puede leerse con fruto comprendiéndola desde un contexto general en que se haya inserta. ¿Es esto una explicación? ¿Es cierto aquello de que la filosofía inglesa se lee y la alemana se deletrea? No lo sé. Como ya digo, me siento incapaz de hacer un diagnóstico seguro en la materia.

Y de la filosofía del Derecho alemana actual ¿qué decir? De la que podríamos llamar filosofía del Derecho clásica no queda nada, como nada o casi nada queda de la vigorosa vida filosófica alemana tal como se desarrollaba tradicionalmente en los seminarios universitarios o en círculos privados. De ello se encargaron Hitler y sus acólitos: descabezando las Universidades y privándolas de sus mejores maestros, insuflando en las juventudes el desprecio por toda labor abstracta o intelectual, y finalmente, suprimiendo la filosofía del Derecho como materia de examen, lo que equivalía a eliminarla también de los planes de estudio de la facultad de Derecho. A lo que hoy asistimos en Alemania es a algunos esfuerzos denodados por recobrar la tradición perdida. Son esfuerzos loables, muy meritorios y en alguna ocasión incluso excelentes. Pero lo que hoy caracteriza a la filosofía alemana es, sin duda, la influencia del pensamiento norteamericano. A esta influencia se debe el auge insospechado de la historiografía pragmática, y sobre todo, de la sociología más empírica, que es la faz que hoy muestra hacia el exterior la ciencia alemana.

Usted ha sido siempre partidario de una teoría del Derecho que acentúe fuertemente su dimensión histórica y social. Sin embargo, parece que, tras Kelsen, las teorías del Derecho de más impacto en nuestro siglo no se han desarrollado en esa dirección, sino más bien en la de un análisis cada vez más refinado de la estructura interna del ordenamiento jurídico. ¿A qué teorías del Derecho del siglo XX se encuentra usted más próximo? ¿Cree previsible un auge de las teorías sociales del Derecho en el próximo futuro? ¿Sobre qué parámetros, en su opinión, habrían de construirse? 
Es verdad que, en los últimos tiempos, se entiende como objetivo principal de la reflexión jurídica el análisis de la estructura del Derecho en tanto que ordenamiento de la vida en común, y de las normas en sí como parte integrante de dicho ordenamiento. Lo que yo niego es que este análisis sea filosofía del Derecho. Ya a finales del siglo pasado tuvimos algo semejante en la «Allgemeine Rechtslehre» de A. Merkel, y lo que entonces se argumentaba en su contra tiene todavía hoy validez: para proceder al examen de un objeto, hace falta saber, ante todo, qué es ese objeto, siquiera para delimitarlo de otras zonas del ser. Este examen formal del ordenamiento jurídico y de sus normas podrá ser analítica jurídica, teoría pura del Derecho o como quiera donominárselo, lo que no es es filosofía del Derecho. La filosofía del Derecho tiene problemas específicos: qué es el Derecho y qué es Derecho, qué es validez, qué es y cómo se fundamenta la obligatoriedad jurídica, y muchos más. Son problemas comunes, en parte, a otros ordenamientos de la vida humana en común, pero que revisten un carácter propio por la razón de que el Derecho es producto de un grupo humano concreto en un momento histórico concreto también, y sólo teniendo en cuenta este hecho y desde su perspectiva pueden plantearse y contestarse adecuadamente estos problemas.

\section{4}

En 1979 escribió usted un trabajo, La obediencia al Derecho, en el que mantenía al respecto una tesis que bien puede calificarse de radical: «mientras que no hay un fundamento ético absoluto para la obediencia al Derecho, sí hay un fundamento ético absoluto para su desobediencia»; dicho fundamento está constituido por «la conciencia ética individual» que es «un fenómeno esencialmente personal». Tras la polémica originada por dicho trabajo ¿considera que su tesis debiera ser modificada en algún sentido? ¿Estima que la polémica en cuestión ha permitido poner de manifiesto algún elemento importante de dicha problemática que usted no hubiera considerado?

Sigo fiel a mi tesis de que no hay fundamento ético absoluto para la obediencia al Derecho, y sí, en cambio, para su desobediencia.

Hay que tener bien presente que no hablo de un fundamento ético cualquiera, sino de un fundamento ético «absoluto» para la obediencia al Derecho, es decir, no de un fundamento que basta a una o más personas, incluso a una mayoría, sino de un fundamento ético que de por sí sea vinculante para toda persona con un uso normal de razón. El argumento tan socorrido, por ejemplo, de que hay que obedecer al Derecho por ser esta obediencia la garantía de la estabilidad y permanencia del orden establecido, ¿dice algo a grandes masas de población que padecen institucionalmente bajo la estabilidad y permanencia de este orden social? ¿Es que ésta como todas las fundamentaciones del Derecho por su función, con independiencia de su contenido, no son, más bien, como dice Alf Ross, «formas degeneradas del iusnaturalismo)»?

Sí creo, en cambio, que hay un fundamento ético absoluto para desobedecer en algunos casos al Derecho, a saber, siempre que el cumplimiento de una norma jurídica contradiga los imperativos de la conciencia ética in- 
dividual. Esta conciencia ética es lo que hace al hombre hombre, lo que presta valor a su personalidad individual, y frente a ella no prevalece ninguna realidad normativa. Aun a riesgo de repetirme, diré, una vez más, que el desobediente ético no es un predicador político, no trata de ganar a nadie para sus ideas; no persigue tampoco la derogación o reformas de normas o instituciones, como es el caso en la llamada desobediencia civil. Lo único que. el desobediente ético pretende es la paz consigo mismo, y por eso, está dispuesto a sufrir la pena que lleva aparejada la infracción jurídica. Es lo que se ha llamado por boca autorizada «el derecho a padecer». En la desobediencia ética al Derecho alienta, es verdad, un momento de auténtico dramatismo, que no debe pasarse por alto. El que por imperativo ético sufre la pena consiguiente a la desobediencia a la ley jurídica, puede dudar un momento de si lo que él tiene por imperativo moral lo es efectivamente, y si no llegará un instante en el futuro en el que piense de modo distinto, de tal manera que la pena que ahora sufre carezca en realidad de sentido. A ello habría que responder, lo que, un día antes de su ejecución por los nazis, se decía a sí mismo John Rittmeister, un resistente alemán: «No pienses en el futuro; ahora, y es lo que importa, estás cumpliendo con tu deber».

Como se ve, no ha variado en nada mi posición inicial, que es la de una fe inquebrantable en la personalidad y autonomía ética del individuo. Entre todos los argumentos acumulados contra mi tesis no he encontrado, hasta ahora, ninguno que me haya hecho vacilar en mi posición.

\section{5}

En los últimos años ha escrito usted diversos trabajos sobre Marx coincidiendo precisamente con un momento de «baja» del marxismo en los medios académicos. Por otro lado, su último libro -que recoge sus más recientes artículos y un trabajo sobre Kant de fecha muy anterior-tiene un título cuyo alcance pudiera pensarse que no es meramente descriptivo: «De Kant a Marx. Estudios de Historia de las ideas». Finalmente, en alguna obra suya de la década de los sesenta pueden leerse frases de «sabor» marxista. Por ejemplo, en Sobre el positivismo jurídico (1967), analizando el iusnaturalismo de la postguerra, ponía de manifiesto cómo sus raíces se hallan en un fenómeno sociológico: «el derrumbamiento del mundo ético y político de la burguesía industrial del siglo XX. El clamor por un Derecho natural o por una ética jurídica material absoluta es solo un síntoma más de la inseguridad y de la desorientación de una clase social agnóstica, carente de fe en sus destinos históricos». ¿Hay alguna razón de fondo que permita unir estos tres aspectos de su obra que acabamos de señalarle? ¿Ha sido o es realmente importante en su obra la influencia de Marx? ¿Cómo juzga el marxismo contemporáneo?

Para comenzar, quisiera dejar sentado, que el título «De Kant a Marx» para la última colección publicada de artículos y ensayos míos no es original mío, sino que se debe a una inteligente sugerencia del director de la serie en que apareció el volumen. Sí puedo asegurar, sin embargo, que con dicho título no se quiere aludir naturalmente, ni a una interdependencia de ideas entre Kant y Marx, ni mucho menos a un condicionamiento filosófico entre 
ambos. Lo único que se ha querido indicar con el título han sido los límites cronológicos y temáticos en que se movían los trabajos incluidos en el libro.

Respecto a mi insistencia en tomar a Marx como objeto de estudio, sólo puedo decir lo que sigue. El lector atento habrá podido observar que todos mis trabajos sobre el marxismo -en breve aparecerá otro- tienen como objeto tan sólo al «Marx joven», anterior a 1848, y únicamente en relación con las corrientes filosóficas de su tiempo. Y es que el Marx que a mí me interesa es el «joven hegeliano de izquierda» que con D. F. Strauss, L. Feuerbach, Br. Bauer, H. Hess, M. Stirner, van a imponer un sello a una época, la posthegeliana, que a mí siempre me ha fascinado. Casi todos discípulos directos de Hegel, intentan desde dentro hacer saltar en pedazos la construcción secular del maestro. Son los «últimos filósofos», como los denominaría M. Hess, existencias desgarradas, a los que se les veda la docencia universitaria y se les confiscan sus libros, que viven en una miseria material que aún hoy nos estremece, pero incapaces de compromiso y guiados tan sólo por las exigencias de su verdad. Entre ellos y en primera fila se encuentra Marx, el gran debelador de Hegel, el seguidor y contradictor de Feuerbach, el crítico despiadado de Br. Bauer «y consortes». En una época de iracundia y disputas interminables, Marx es el único que ve con claridad la línea que lleva al futuro y que presiente ya las conmociones que aguardan a la sociedad europea.

En la encuesta se reproduce también un párrafo de un lejano trabajo mío, en el que trataba de explicar el pseudorenacimiento del Derecho natural en la última postguerra, buscando una relación con la sociedad de la época. En esta explicación que sólo era y quería ser sociológica, se ha encontrado un cierto «sabor» marxista. Por mi parte, yo no creo que para echar de ver la naturaleza de la sociedad de la última postguerra haya que situarse uno en un determinado punto de vista político, sino sólo abrir bien los ojos y ver lo que realmente ha acontecido ante nosotros. Una sociedad que había sido herida hasta los últimos estratos de su dignidad por una dictadura inclemente, que había sufrido en su propia carne los horrores y los crímenes de una guerra sin sentido, carente de los medios materiales más indispensables, destruídos todos los lazos y relaciones humanas, sin fe en su destino histórico, una sociedad así ¿no es natural que ansíe y salude con júbilo la existencia de un pretendido catálogo de verdades intemporales tal como lo ofrecía el iusnaturalismo renovado? Estas supuestas verdades no sirven y no han servido de hecho para fundamentar la cohesión social ni para dar pautas al obrar colectivo; pero sí han constituído una aparente justificación a toda una serie de existencias deleznables.

En la teoría del Derecho actual parece existir una cierta tendencia (pensamos al decir esto en autores como Dworkin, convertido en auténtica «estrella» de la Filosofía del Derecho de los últimos años) a abandonar, o superar, el positivismo jurídico y a volver a poner en circulación tesis seguramente iusnaturalistas. ¿Cómo valora usted dicha tendencia? ¿Cree que la misma guarda algún tipo de semejanza con el iusnaturalismo de la inmediata postguerra? ¿Plantean autores como Dworkin argumentos que hagan tam- 
balearse a concepciones netamente iuspositivistas como la suya? ¿Qué hay en su opinión de verdaderamente novedoso en esta nueva teoría del Derecho?

La pregunta contiene dos temas bien deslindados, y en consecuencia, voy a responder también a ambos separadamente.

La primera parte de la pregunta se refiere a un supuesto renacimiento del Derecho natural en nuestros días, y si, dado el caso, este renacimiento guardaría relación con el auge temporal del iusnaturalismo como consecuencia de la última guerra. Ya es sabida la frase de Jean Paul: «toda feria del libro y toda guerra traen consigo nuevos tratados de Derecho natural». Claro está, que Jean Paul no quería decir con ello que la guerra en sí fuera causa de nuevos tratados de Derecho natural, sino que quería aludir a la conciencia que genera en la sociedad las matanzas y los desafueros que acarrean siempre las guerras. Esta conciencia es también la que hizo renacer tras la última guerra toda suerte de teorías iusnaturalistas. La situación pasiva e inerme de toda una sociedad ante los horrores de una guerra encarnizada hizo clamar por un sistema de verdades absolutas, como las que aparentemente ofrecía el Derecho natural, que sirvieran para dar sentido a la existencia individual y colectiva. Hoy nos encontramos en una situación muy diferente y es, por eso, que no asistimos a un nuevo renacer iusnaturalista, y que las raras construcciones de Derecho natural sean, más bien, algo así como plantas exóticas en nuestro panorama jurídico actual. Y es que, mientras la conciencia social de la última postguerra era, como hemos visto, una conciencia social pasiva, hoy vivimos, en cambio, una conciencia social que pudiéramos llamar activa. Estamos insertos en una sociedad sacudida por una profunda crisis: una sociedad competitiva, en la que la distribución y goce de los bienes materiales están determinados anónimamente por los poderes económicos, una sociedad de la que están desapareciendo paulatinamente las relaciones humanas y las formas en que se habían institucionalizado tradicionalmente. Pero una sociedad, y esto es lo decisivo, con una voluntad de pervivencia única en la historia, y que pone al servicio de este fin todos los medios de que dispone. Entre estos medios cuenta, sobre todo, la legislación, adaptada a cada caso concreto y panacea, por eso, de todas las crisis y dificultades. Es lo que yo antes llamaba conciencia activa. Es una conciencia pragmática que no busca verdades absolutas que presten sentido a la vida en común, sino fórmulas concretas que, de momento, aseguren la pervivencia y la continuidad de las relaciones de poder. Y así hay leyes de mayoría de edad, de divorcio, de promoción o restricción de las importaciones y exportaciones, de educación... Leyes todas pensadas para una necesidad determinada o para hacer frente a una situación concreta. Nunca se ha visto una proliferación semejante de la actividad legislativa, porque nunca tampoco se ha conocido una sociedad como la actual, falta de todo proyecto histórico y preocupada tan sólo por mantenerse en pie, aunque sea en equilibrio inestable. No; estamos lejos de las veleidades iusnaturalistas, de la apetencia de verdades intemporales, y hemos entrado ya de lleno en la época del positivismo jurídico. En una época en la que el Derecho positivo, pensado como un instrumento dúctil y fugaz, sirve para mantener sin más problemas ni más justificación una situación concreta. 
La segunda cuestión es harto más espinosa, ya que se trata de considerar la obra de un profesor norteamericano, Ronald Dworkin, enraizada por tanto en un ámbito jurídico concreto -judge-made-law-, common law, desde la perspectiva de un concepto, como el de Derecho natural, nacido en un mundo jurídico también concreto y muy diferente, como es el del Derecho codificado.

Lo equívoco del problema mismo se echa de ver enseguida en la circunstancia de que, siendo todos los juristas anglosajones positivistas en el estricto sentido de la palabra, es decir, creyendo que el Derecho es obra humana, y por tanto, contingente y perfectible, la obra de Dworkin se centra, según propia confesión del autor, en un ataque frontal contra el positivismo jurídico. ¿Cómo es esto posible? La respuesta hay que buscarla en un malentendido teminológico, en que lo que Dworkin denomina «positivismo jurídico» no es exactamente lo mismo que lo que nosotros entendemos con esta expresión. Lo que Dworkin entiende por positivismo jurídico nos lo dice él mismo con las siguientes palabras: «Legal positivism rejects the idea that legal rights can pre-exist any form of legislation; it rejects the idea, that individuals or groups can have rights in adjudication other than the rights explicitly provided in the collection of explicit rules that compose the whole of a community's law». Es decir, que «positivismo jurídico» no significa simplemente que el Derecho es obra humana, sino algo más, lo que entre nosotros se ha llamado y se sigue llamando «positivismo de la ley»: toda norma producida de acuerdo con el sistema formal de producción establecido es norma jurídica y fuente única de derechos y obligaciones. Es un «positivismo» radical que puede llevar a consecuencias insospechadas. «La ley más infame ha de ser tenida por obligatoria, siempre que haya sido producida de modo formalmente correcto», diría ya Bergbohm con palabras bien conocidas. Consciente quizás de estas posibles consecuencias, y escribiendo en un mundo jurídico que reconoce la discrecionalidad judicial, Dworkin añade al texto legal que el juez aplica un «standard», un «principio» que si se tiene en cuenta o es observado es sólo por ser «a requiriment of justice or fairness or some other dimension of morality». Este «principio» Dworkin no se cansa de repetirlo- no es obligatorio ni vinculante como lo son las normas jurídicas; el juez escoge y presta validez al que estima más adecuado entre los que él conoce, o bien al que estima también más adecuado si concurren varios, análogos o contradictorios. Para poner esto más claro, Dworkin aduce repetidas veces un famoso caso judicial. Una persona reclama judicialmente una herencia, acompañando un testamento perfectamente legal en el que se le instituye como heredero universal; el testador, sin embargo, había muerto a manos del heredero, y basándose en ello el juez rechaza la demanda de éste. No por razón de la ley, ya que el testamento poseía todos los requisitos exigidos por ésta, sino apelando al «principio», no contenido en ningún texto legal, pero que el juez estima válido, de que «nadie puede extraer provecho de su propia acción delictiva». Este «principio», como el de que toda persona es responsable de los daños causados por ella misma u obedeciendo órdenes suyas» y muchos más, figuran, por así decirlo, al lado de las normas jurídicas en sentido estricto, no poseen la obligatoriedad de éstas, pero se hallan siempre a disposición del juez que entiende del caso. 
Ahora bien, ¿es esto Derecho natural? Difícilmente podrá darse a la pregunta una respuesta afirmativa. Los «principios» de Dworkin no son reglas de validez absoluta extraídas por el raciocinio de un orden universal de las cosas, sino sólo «standards», motivaciones últimas de muy diversa índole, que el juez puede o no tomar en consideración. Y no es, por eso, extraño, ni mucho menos, que el mismo Dworkin se haya declarado recientemente ajeno a toda especulación iusnaturalista.

\section{7}

En los últimos años -pongamos, en la última década- ha incrementado usted considerablemente su ritmo de producción. ¿Cuáles son las razones de ello? ¿Cuáles van a ser sus próximos trabajos? Finalmente, ¿cuál considera usted que es su principal contribución en el campo de la filosofía del Derecho?

El hecho de que mi producción científica haya sido menor anteriormente de lo que lo es en la actualidad puede explicarse sencillamente: falta de tiempo y autocensura. Cuando yo estaba en activo tomé muy a pecho las clases y los demás deberes de la docencia universitaria, lo que me restó mucho tiempo para otros menesteres; si a ello se añade que durante siete años he sido profesor visitante de la Universidad de Heidelberg, con lo que ello implica de viajes y desplazamientos, se comprenderá que no he tenido demasiada ocasión para dedicarme a publicaciones. Y sin embargo, no puede decirse que hayan sido años perdidos. Durante ellos, y aprovechando, sobre todo, los grandes fondos de las bibliotecas alemanas, tomé notas y apuntes, extractos, consulté obras poco conocidas e incluso fui trazando mentalmente los grandes esquemas de futuros trabajos. Otra cosa es la autocensura. Yo no publico un trabajo sin estar satisfecho de él -lo que no quiere decir, desde luego, que mi satisfacción sea, ni mucho menos, garantía de la bondad de lo publicado-, sin haber comprobado, y más de una vez, las citas y opiniones contenidas en el trabajo. Esto explica que trabaje lentamente y con muchas pausas; y no es de extrañar, por ello, que tenga arrinconados trabajos prácticamente terminados, pero en los que no he podido comprobar algún extremo que tengo por decisivo.

Respecto a mis futuros trabajos, tengo terminado y aparecerá en breve «Ludwig Feuerbach y los orígenes filosóficos del marxismo» y actualmente trabajo en «La jurisprudencia de los intereses», que viene a ser un paralelo del trabajo sobre la jurisprudencia conceptual que di a luz hace años. Además está «El neokantismo jurídico axiológico» que saldrá en al «Anuario» próximo, «Rudolf von Jhering y el problema del método jurídico» y «Der Entfremdungsbegriff bei Hegel» que va a salir en una Festschrift alemana. Creo que es imposible, sobre todo en España, dar un paso fructífero en la filosofía del Derecho sin un sólido conocimiento anterior de sus supuestos metódicos y de las polémicas que, en su día, se desataron en torno a alguno de ellos. 